\title{
HLA-DR expression in neonates after cardiac surgery under cardiopulmonary bypass: a pilot study
}

Alexis Chenouard ${ }^{1 *}$, Cécile Braudeau ${ }^{2,3}$, Nicolas Cottron ${ }^{1}$, Pierre Bourgoin ${ }^{1}$, Nina Salabert ${ }^{2,3,4}$, Antoine Roquilly ${ }^{5}$, Régis Josien ${ }^{2,3,4}$, Nicolas Joram ${ }^{1}$ and Karim Asehnoune ${ }^{5}$

* Correspondence: alexis.chenouard@chu-nantes.fr ${ }^{1} \mathrm{CHU}$ Nantes, Service de Réanimation Pédiatrique, Nantes, France

Full list of author information is available at the end of the article

\begin{abstract}
Monocyte HLA-DR expression has been reported as a marker of immunosuppression and a predictor of sepsis development. However, to date, there is no report on monocyte HLA-DR monitoring exclusively in neonates ( $<28$ days of life) who underwent cardiac surgery under cardiopulmonary bypass (CPB), which have a high risk of nosocomial infection. In this pilot study, we studied nine neonates with a diagnosis of congenital heart disease requiring surgery under CPB. There was a significant reduction in monocyte HLA-DR expression for the first two postoperative days, as compared to preoperatively $(p=0.004)$. Moreover, neonates who displayed an episode of $\mathrm{NI}$ had a dramatically lower HLA-DR expression at day 4, as compared to neonates without $\mathrm{NI}$ (4257 AB/C [2220-5895] vs 14,947 AB/C [9858-16,960]; $p=0.04)$. Our preliminary results could indicate that HLA-DR expression may be a useful biomarker of immunosuppression-induced secondary infection after CPB in neonates.
\end{abstract}

\section{Background}

The pro-inflammatory response that accompanies the onset of critical illness often occurs concurrently with a compensatory anti-inflammatory response. When severe and persistent, this anti-inflammatory response has been termed immunoparalysis. The diminished monocyte human leukocyte antigen-DR (HLA-DR) expression on cell surface is proposed to reflect immunoparalysis in critically ill patients $[1,2]$. To date, HLA-DR expression has been assessed in adults as a predictor of septic complications after various injuries [3-6]. In pediatric cardiac surgery, HLA-DR expression has been examined in two studies $[7,8]$. However, the results were principally limited by concern related to age of patient with a large heterogeneity [8] or non-inclusion of children younger than 3 months [7]. To our knowledge, no study has specifically focused on HLA-DR expression on circulating monocytes among neonates who underwent cardiac surgery under cardiopulmonary bypass (CPB), which have a high risk of nosocomial infection (NI) [9]. In this pilot study, we investigated the kinetic of monocyte HLA-DR expression in this population and described the relationship between monocyte HLA-DR expression and the subsequent development of NI.

(C) The Author(s). 2018 Open Access This article is distributed under the terms of the Creative Commons Attribution 4.0 International License (http://creativecommons.org/licenses/by/4.0/), which permits unrestricted use, distribution, and reproduction in any medium, provided you give appropriate credit to the original author(s) and the source, provide a link to the Creative Commons license, and indicate if changes were made. 


\section{Methods}

Blood samples were collected from neonates preoperatively at line insertion, and 1, 2, 3 , and 4 days after the end of $\mathrm{CPB}$ on immunology laboratory working days (Monday to Friday). The number of HLA-DR molecules per monocyte $(\mathrm{AB} / \mathrm{c})$ was determined immediately after sample collection (i.e., within $90 \mathrm{~min}$ ) by flow cytometry on whole blood using a standardized method with a Quantibrite phycoerythrin fluorescence quantitation kit (Quantibrite anti HLA-DR/Anti Monocytes CD14, BD Biosciences, Le Pont de Claix, France), as previously described [10, 11]. Blood samples for cytokine assays were immediately centrifuged, and the plasma was stored at $-80{ }^{\circ} \mathrm{C}$. Cytokine concentrations in the plasma (IL-6, IL-8, and IL-10) were measured by multiplex immunoassay according to the manufacturer's protocol (Merck Millipore, Molsheim, France). Immunological analysis was conducted blind, and clinical data were not available to the immunology staff before the end of the study.

NI including catheter-related bloodstream infections, ventilator-associated pneumonia, and sternal wound infections were defined based on the Center of Disease Control (CDC) and National Nosocomial Infections Surveillance criteria [12] and were prospectively recorded during the PICU stay or within 30 days after surgery. All parents were informed of the project and written consent was waived. The study was approved by the local ethics committee of the University Hospital of Nantes.

\section{Statistics}

Statistical analyses were performed using GraphPad Prism software (GraphPad, La Jolla, CA). The Kruskal-Wallis test was used for comparisons of multiple groups (preoperatively, $1,2,3$, and 4 days after CPB). Dunn's multiple comparisons test was used as a post hoc test for intergroup comparisons. Continuous nonparametric variables were expressed as medians (extremes values). The Mann-Whitney test was used to compare two independent groups on day 4 (infected versus non-infected patients). Significance was defined as $p$-value less than 0.05 .

\section{Results}

Table 1 depicts the baseline characteristics of the nine neonates included in this study that underwent congenital cardiac surgery under CPB. As shown in Fig. 1, there was a significant reduction in monocyte HLA-DR expression for the first two postoperative days, as compared to preoperatively $(p=0.004)$. Among the three patients $(33 \%)$ who displayed an episode of NI (two sternal wound infections and one ventilator-associated pneumonia respectively on days 3,4 , and 8 after $\mathrm{CPB}$ ), we observed a dramatic lower HLA-DR expression at day 4, as compared to patients without NI (4257 AB/c [2220-5895] vs $14,947 \mathrm{AB} / \mathrm{c}$ [9858-16,960]; $p=0.04$ ) (Fig. 1). Of note, among infected patients, two present low HLA-DR values before surgery. As lower gestational age and birth weight was known to be associated with diminished HLA-DR expression [13], we analyzed the preoperatively HLA-DR expression according to the gestational age and the birth weight of patients, and we did not find any correlation in our cohort (data not shown). Finally, ratio of HLA-DR expression between day 4 and days 1-2 (minimal value between day 1 and day 2 ) was $1.5[1.2-2.1]$ in the infected group compared to 2.5 [1.4-3.2] in the non-infected group $(p=0.23)$. 
Table 1 Characteristics of patients $(n=9)$

\begin{tabular}{|c|c|}
\hline \multicolumn{2}{|l|}{ Demographics } \\
\hline Age (days) & $12[6-23]$ \\
\hline Weight (kg) & $2.9[2.0-4.0]$ \\
\hline Male, $n(\%)$ & $7(78 \%)$ \\
\hline Gestational age < 36 weeks, $n(\%)$ & $2(22 \%)$ \\
\hline Genetic abnormality, $n(\%)$ & $0(0 \%)$ \\
\hline Cyanotic congenital heart defects, $n(\%)$ & $5(56 \%)$ \\
\hline Lymphocyte cell count preoperatively $\left(/ \mathrm{mm}^{3}\right)$ & $5350[2000-7510]$ \\
\hline \multicolumn{2}{|l|}{ Characteristics of surgery } \\
\hline RACHS-1 score ${ }^{a}$ & $4[3-6]$ \\
\hline Time on cardiopulmonary bypass (min) & $164[54-272]$ \\
\hline Aortic cross-clamp time (min) & $85[0-182]$ \\
\hline Hypothermia $\left(20-28^{\circ} \mathrm{C}\right), n(\%)$ & $5(56 \%)$ \\
\hline \multicolumn{2}{|l|}{ Characteristics during the PICU stay after surgery } \\
\hline Use of corticoids during the first $48 \mathrm{~h}, n(\%)$ & $6(67 \%)$ \\
\hline Extracorporeal membrane oxygenation support, $n(\%)$ & $1(11 \%)$ \\
\hline Delayed closure of sternum, $n(\%)$ & $4(44 \%)$ \\
\hline Peak Vasoactive-Inotropic score during the first $48 \mathrm{~h}^{\mathrm{b}}$ & $11[2-56]$ \\
\hline Positive fluid balance at day $2, n(\%)$ & $2(22 \%)$ \\
\hline Acute kidney injury at day $2^{c}, n(\%)$ & $4(44 \%)$ \\
\hline Lymphocyte cell count at day $2\left(/ \mathrm{mm}^{3}\right)$ & 1830 [1100-4000] \\
\hline Time on mechanical ventilation (days) & $4[2-10]$ \\
\hline Nosocomial infection, $n$ (\%) & $3(33 \%)$ \\
\hline PICU length of stay (days) & $8[4-80]$ \\
\hline Death, $n(\%)$ & $1(11 \%)$ \\
\hline \multicolumn{2}{|c|}{$\begin{array}{l}\text { Data are expressed as medians (extremes values) or } n \text { (\%) } \\
\text { a RACHS-1 (Risk-Adjusted classification for Congenital Heart Surgery) score reflects procedure complexity (range, 1-6), } \\
\text { with higher scores correlating with more complex surgery [15] } \\
\text { bVasoactive-Inotropic score }=(1 \times \text { dopamine }[\mu \mathrm{g} / \mathrm{kg} / \mathrm{min}]+1 \times \text { dobutamine }[\mu \mathrm{g} / \mathrm{kg} / \mathrm{min}]+100 \times \text { epinephrine }[\mu \mathrm{g} / \mathrm{kg} / \mathrm{min}] \\
+100 \times \text { norepinephrine }[\mu \mathrm{g} / \mathrm{kg} / \mathrm{min}]+10 \times \text { milrinone }[\mu \mathrm{g} / \mathrm{kg} / \mathrm{min}]+10,000 \times \text { vasopressin }[\mathrm{U} / \mathrm{kg} / \mathrm{min}] \text { ) [16] } \\
\text { "Acute kidney injury is defined by using the pediatric-modified RIFLE criteria ("Failure" category) [17] }\end{array}$} \\
\hline
\end{tabular}

We next evaluated the inflammatory cytokine response after CPB. As shown in Fig. 2, circulating levels of pro-inflammatory cytokines IL-6 and IL-8 were significantly higher on day 1 as compared to preoperatively $(p<0.01)$, whereas the release of anti-inflammatory IL-10 cytokine was not affect by CPB. At day 4, patients with NI showed increased IL- 6 and IL-8 release as compared to patients without NI (70 pg/ml [33-135] vs $19 \mathrm{pg} / \mathrm{ml}$ [14-27] and $43 \mathrm{pg} / \mathrm{ml}$ [42-43] vs $24 \mathrm{pg} / \mathrm{ml}$ [15-36], respectively; $p=0.04$ ) (Fig. 2).

\section{Discussion}

In this pilot study, we report that neonates had a dramatic reduction in HLA-DR expression on circulating monocytes during the first two postoperative days after $\mathrm{CPB}$, and those with prolonged decreased HLA-DR in the early postoperative period (day 4) could represent a subpopulation at greatly increased risk of later NI. Moreover, immunoparalysis described here after neonatal $\mathrm{CPB}$ accompanies a pro-inflammatory response, illustrated by high circulating levels of IL- 6 and IL-8. This increase in pro-inflammatory cytokines IL-6 and IL-8 $24 \mathrm{~h}$ after CPB is consistent with previous studies in pediatric cardiac surgery [14]. 


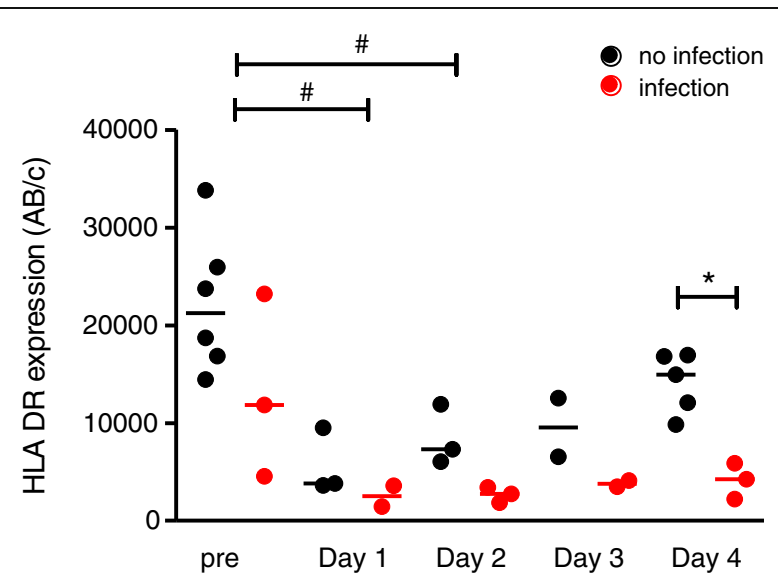

Fig. 1 HLA-DR expression in neonates after cardiopulmonary bypass. Each point in red represents expression of HLA-DR in patients who displayed an episode of NI. The Kruskal-Wallis test was used for comparisons of multiple groups, with Dunn's multiple comparisons test for intergroup comparisons (preoperatively, 1, 2, 3 and 4 days after CPB) (\# $p<0.05)$. The Mann-Whitney test was used to compare infected versus non-infected patients on day $4\left({ }^{*} p<0.05\right)$

The main limitation of this preliminary study concerns the fact that HLA-DR values were not censored after NI diagnosis given the small number of patients included. These promising findings warrant thus a larger confirmatory trial (NCT03309839) before HLA-DR expression can be introduced in the clinical practice as a useful biomarker of immunosuppression-induced after $\mathrm{CPB}$ in neonates.

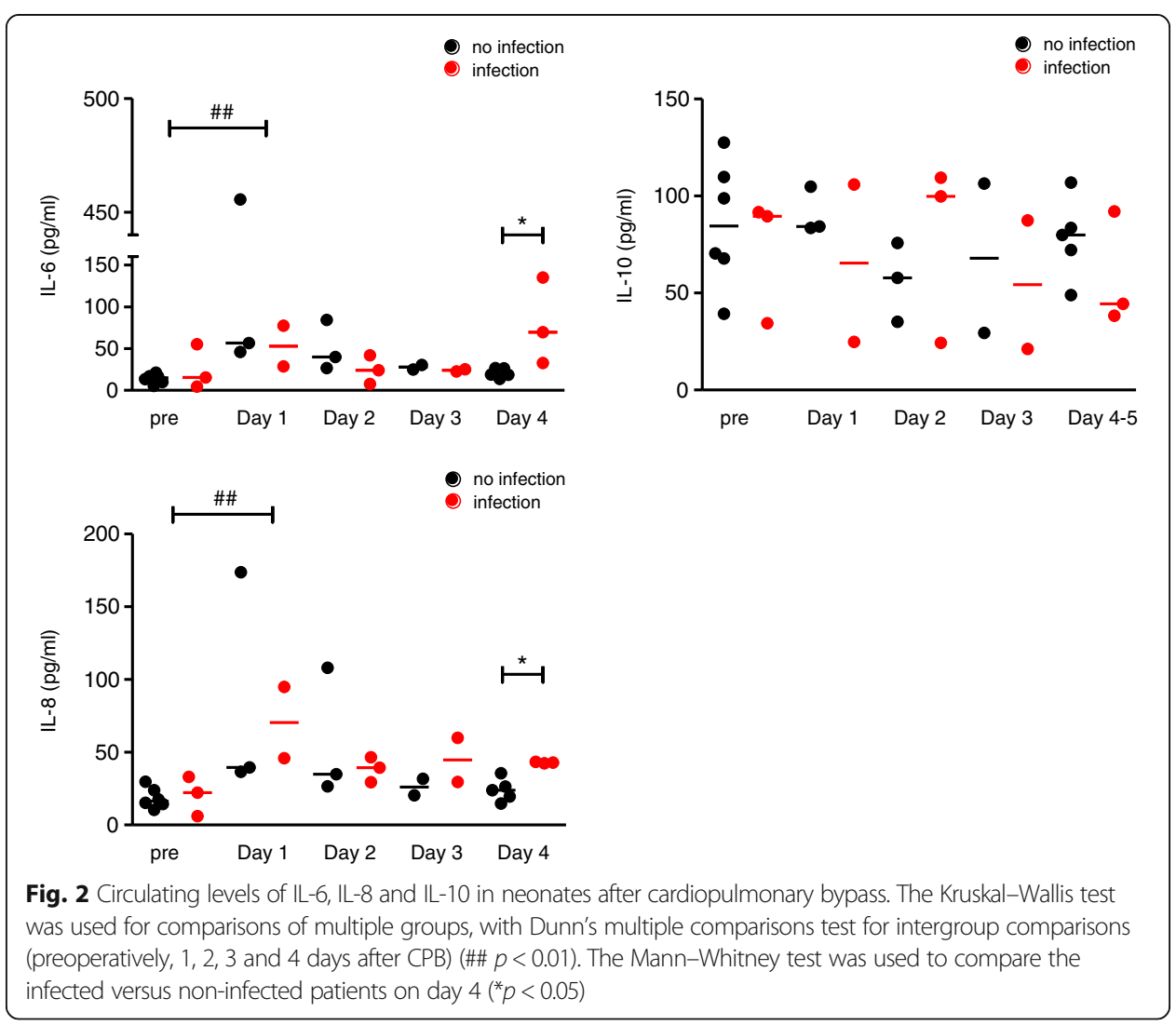


Funding

None.

Authors' contributions

AC designed the study, performed the statistical analysis, and drafted the manuscript. CB and NS performed the immunological analysis. AC, NC, PB, and NJ collected the clinical data. NC, PB, NJ, RJ, AR, and KA revised it for important intellectual content. All authors approved the final version of the manuscript.

Ethics approval and consent to participate

All parents were informed of the project which was approved by the local ethics committee of the University Hospital of Nantes.

\section{Consent for publication}

Written parental consent to publish has been obtained from all children included in the study.

\section{Competing interests}

The authors declare that they have no competing interests.

\section{Publisher's Note}

Springer Nature remains neutral with regard to jurisdictional claims in published maps and institutional affiliations.

\section{Author details}

${ }^{1} \mathrm{CHU}$ Nantes, Service de Réanimation Pédiatrique, Nantes, France. ${ }^{2} \mathrm{CHU}$ Nantes, Laboratoire d'Immunologie, CIMNA, Nantes, France. ${ }^{3}$ Centre de Recherche en Transplantation et Immunologie, UMR 1064, INSERM, Université de Nantes, Nantes, France. "LabEx IGO "Immunotherapy, Graft, Oncology", Nantes, France. ${ }^{5} \mathrm{CHU}$ Nantes, Pôle anesthésie réanimations, Service d'anesthésie réanimation chirurgicale, Hôtel Dieu, Nantes, France.

Received: 13 October 2017 Accepted: 14 December 2017

Published online: 11 January 2018

\section{References}

1. Bronicki RA, Hall M (2016) Cardiopulmonary bypass-induced inflammatory response: pathophysiology and treatment. Pediatr Crit Care Med 17(8 Suppl 1):S272-S278

2. Hall MW, Greathouse KC, Thakkar RK, Sribnick EA, Muszynski JA (2017) Immunoparalysis in pediatric critical care. Pediatr Clin N Am 64(5):1089-1102

3. Lukaszewicz AC, Grienay M, Resche-Rigon M, Pirracchio R, Faivre V, Boval B, Payen D (2009) Monocytic HLA-DR expression in intensive care patients: interest for prognosis and secondary infection prediction. Crit Care Med 37(10):2746-2752

4. Monneret G, Lepape A, Voirin N, Bohe J, Venet F, Debard AL, Thizy H, Bienvenu J, Gueyffier F, Vanhems P (2006) Persisting low monocyte human leukocyte antigen-DR expression predicts mortality in septic shock. Intensive Care Med 32(8):1175-1183

5. Landelle C, Lepape A, Voirin N, Tognet E, Venet F, Bohe J, Vanhems P, Monneret G (2010) Low monocyte human leukocyte antigen-DR is independently associated with nosocomial infections after septic shock. Intensive Care Med 36(11):1859-1866

6. Strohmeyer JC, Blume C, Meisel C, Doecke WD, Hummel M, Hoeflich C, Thiele K, Unbehaun A, Hetzer R, Volk HD (2003) Standardized immune monitoring for the prediction of infections after cardiopulmonary bypass surgery in risk patients. Cytometry B Clin Cytom 53(1):54-62

7. Gessler P, Pretre R, Burki C, Rousson V, Frey B, Nadal D (2005) Monocyte function-associated antigen expression during and after pediatric cardiac surgery. J Thorac Cardiovasc Surg 130(1):54-60

8. Allen ML, Peters MJ, Goldman A, Elliott M, James I, Callard R, Klein NJ (2002) Early postoperative monocyte deactivation predicts systemic inflammation and prolonged stay in pediatric cardiac intensive care. Crit Care Med 30(5):1140-1145

9. Grisaru-Soen G, Paret G, Yahav D, Boyko V, Lerner-Geva L (2009) Nosocomial infections in pediatric cardiovascular surgery patients: a 4-year survey. Pediatr Crit Care Med 10(2):202-206

10. Docke WD, Hoflich C, Davis KA, Rottgers K, Meisel C, Kiefer P, Weber SU, Hedwig-Geissing M, Kreuzfelder E, Tschentscher $P$ et al (2005) Monitoring temporary immunodepression by flow cytometric measurement of monocytic HLA-DR expression: a multicenter standardized study. Clin Chem 51(12):2341-2347

11. Demaret J, Walencik A, Jacob MC, Timsit JF, Venet F, Lepape A, Monneret G (2012) Inter-laboratory assessment of flow cytometric monocyte HLA-DR expression in clinical samples. Cytometry B Clin Cytom 84(1):59-62

12. Horan TC, Andrus M, Dudeck MA (2008) CDC/NHSN surveillance definition of health care-associated infection and criteria for specific types of infections in the acute care setting. Am J Infect Control 36(5):309-332

13. Schefold JC, Porz L, Uebe B, Poehlmann H, von Haehling S, Jung A, Unterwalder N, Meisel C: Diminished HLA-DR expression on monocyte and dendritic cell subsets indicating impairment of cellular immunity in pre-term neonates: a prospective observational analysis. J Perinat Med 2014, 43(5):609-618

14. Liu KD, Altmann C, Smits G, Krawczeski CD, Edelstein CL, Devarajan P, Faubel S (2009) Serum interleukin-6 and interleukin-8 are early biomarkers of acute kidney injury and predict prolonged mechanical ventilation in children undergoing cardiac surgery: a case-control study. Crit Care 13(4):R104 
15. Jenkins KJ, Gauvreau K, Newburger JW, Spray TL, Moller JH, lezzoni LI (2002) Consensus-based method for risk adjustment for surgery for congenital heart disease. J Thorac Cardiovasc Surg 123(1):110-118

16. Gaies MG, Gurney JG, Yen AH, Napoli ML, Gajarski RJ, Ohye RG, Charpie JR, Hirsch JC (2010) Vasoactiveinotropic score as a predictor of morbidity and mortality in infants after cardiopulmonary bypass. Pediatr Crit Care Med 11(2):234-238

17. Akcan-Arikan A, Zappitelli M, Loftis LL, Washburn KK, Jefferson LS, Goldstein SL (2007) Modified RIFLE criteria in critically ill children with acute kidney injury. Kidney Int 71(10):1028-1035

Submit your manuscript to a SpringerOpen ${ }^{\circ}$ journal and benefit from:

- Convenient online submission

- Rigorous peer review

Open access: articles freely available online

- High visibility within the field

- Retaining the copyright to your article

Submit your next manuscript at $\gg$ springeropen.com 